\title{
Full-scale Measurement of Wind-field of Civil Engineering Structure
}

\author{
Huang Yuhao \\ Sichuan College of Architectural Technology, International school of technical education, DeYang, \\ Sichuan, 618000 China \\ 2582004193@qq.com
}

Keywords: Field measurement, National stadium, Power spectrum, Scale of turbulence.

\begin{abstract}
This paper makes use of the wind-field full-scale measurement system of civil engineering structure which is based on wireless sensor technology and developed independently, conducts monitoring of the wind speed and direction of the large-longspan cover of the national stadium, and gets the wind-field full-scale measurement. Therefore, such characteristic parameters as average wind speed and direction, gustiness factor, scale of turbulence and pulsating wind power spectrum are got. Through the analysis of the measured data, the results show that there are relative differences between the wind-field on the large-longspan cover and the natural incoming flow characters, which manifests that the non-gaussian characteristic is obvious, the turbulence intensity is larger, the pulsating wind speed power spectrum reaches the peak at higher frequency, and the fluctuation characteristics of the pulsations in space are weak; this paper has proved from the perspective of field measurement.
\end{abstract}

\section{Introduction}

With the progress of structural system, building materials, the design and construction technology, modern architecture develops towards larger height and more span, which makes the engineering structure show such characteristics of low weight, large flexibility, small damping and low natural frequency of vibration, and the wind load often becomes the main load of control structure design. At present, the wind tunnel test method is still the main approach of the study of the structural wind resistance; however, due to the reduced scale model test, there still are a lot of differences between the results gained in the wind tunnel test simulation and field measurement, such as wind tunnel simulation of turbulence is difficult to reach the actual value, or the important parameters of Reynolds number describing fluid characteristics is 2 to 3 orders of magnitude lower than the actual value. In conclusion, wind tunnel test is the most mainstream research method of wind engineering, but it still has many problems. The field measurement is the most direct and reliable method, which can effectively validate and improve the results and simulation method of wind tunnel test and numerical wind tunnel, so as to promote the development of the whole wind engineering research method.

\section{Wind Characteristic Analysis of The Top of Building C}

Wind field of the multi-point synchronous measurement and correlation research generally only in large span bridge engineering in the research, the experimental study is limited to the surface from the open characteristic of wind field under the conditions of landform, along with the increase in urban high-rise building, architectural group interference effect between caused wide attention. When two or more buildings apart is very close, the building will generate fluid surrounding the interference effect of the building under wind load and it is only a building on the prescribed by ritual law carrying a big difference. Has quite a few literature to study the interference effect of building wind load], but most of the research is carried out based on wind tunnel test, and mostly is 
the study of square cross section construction at different position the interference effect of cases, it is difficult to through the spot test to verify the results.

The wind speed meter at the top of building C was installed in 2015, and the data of wind field of the top were obtained in the field measurement of the 5 typhoons. Based on the analysis of wind characteristics of the non-steady wind model, the wind characteristic parameters of the top of the building $\mathrm{C}$ in 5 typhoons were recomputed, and the results of the steady wind model were compared. After the introduction the concept of time-varying average wind, some adjustments need to be done in the calculation formula of various fluctuating wind parameters of non-steady wind model; some commonly used calculating formulas under two kinds of wind speed models are shown in table for analysis of the 5 groups of samples; with the basic interval of 10 minutes and the traditional steady wind model, the wind parameters can be calculated according to the formulas in table 2.1.

Table 2-1 Some commonly used calculating formulas under two kinds of wind speed models

\begin{tabular}{|c|c|c|}
\hline Parameters & Steady wind model & Non-steady wind model \\
\hline Wind speed & $\begin{array}{l}U(t)=\bar{U}+u(t) \\
v(t), w(t)\end{array}$ & $\begin{array}{l}U(t)=\bar{U}+u^{*}(t) \\
v(t)=\bar{v}(t)+v^{*}(t) \\
w(t)=\bar{w}(t)+w^{*}(t)\end{array}$ \\
\hline Average wind speed & $\bar{U}=\frac{1}{T} \int_{0}^{T} U(t) d t$ & $\begin{array}{l}\overline{\bar{U}}=\sum_{j=m}^{N} \frac{1}{T} c_{j}^{u}(t)+r_{u}(t)_{N} \mathrm{Z} \\
\bar{U}=\frac{1}{T} \int_{0}^{T} \bar{U}(t) d t\end{array}$ \\
\hline Variance & $\sigma_{\alpha}^{2}=\frac{1}{T} \int_{0}^{T} \alpha^{2}(t) d t$ & $\sigma_{\alpha *}^{2}=\frac{1}{T} \int_{0}^{T} \alpha^{*^{2}}(t) d t$ \\
\hline $\begin{array}{l}\text { Probability density } \\
\text { function }\end{array}$ & $p(\alpha)=\frac{1}{\sqrt{2 \pi \sigma_{\alpha}}} e^{-\alpha 2 / 2 \sigma_{\alpha}^{2}}$ & $p\left(\alpha^{*}\right)=\frac{1}{\sqrt{2 \pi \sigma_{\alpha^{*}}}} e^{-\alpha * 2 / 2 \sigma_{\alpha^{*}}^{2}}$ \\
\hline Scale of turbulence & $I_{\alpha}=\frac{\sigma_{\alpha}}{\bar{U}}$ & $I_{\alpha *}=\frac{\sigma_{\alpha^{*}}}{\overline{U^{*}}}$ \\
\hline
\end{tabular}

(1) The wind speed and the direction of the wind

The time history of wind speed and wind direction of the 5 groups of measured samples are shown in Figure 2-1. It can be seen that in addition to sample 2, the wind speed and direction of the other 4 groups are relatively steady, and the wind speed is basically kept at more than $10 \mathrm{~m} / \mathrm{s}$. As the pulsation of measured wind speed and direction of the sample 2 is larger, the direction is northwest, the northwest area to the measured location is mountainous region, and there is 8-floor high-rise building, certain disturbances are produced to the measured wind field by these factors and the building. 


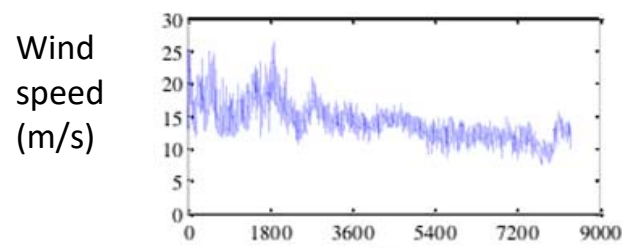

Time(s)

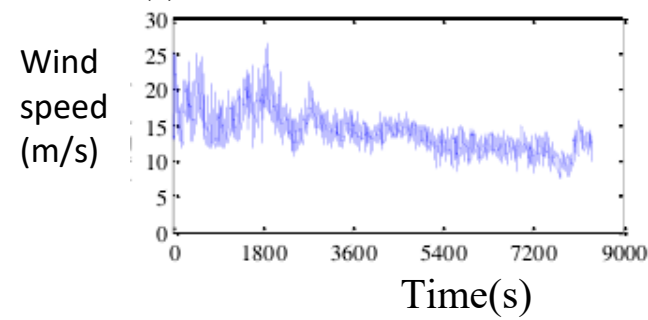

a) Sample 1

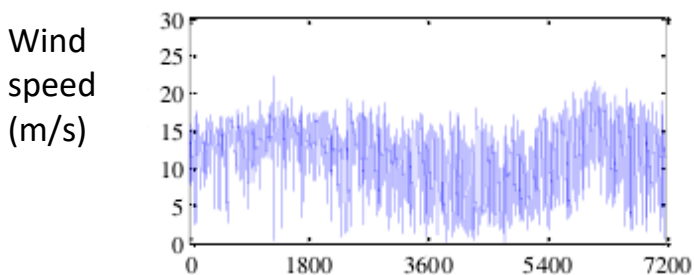

Time(s)

b) Sample 2

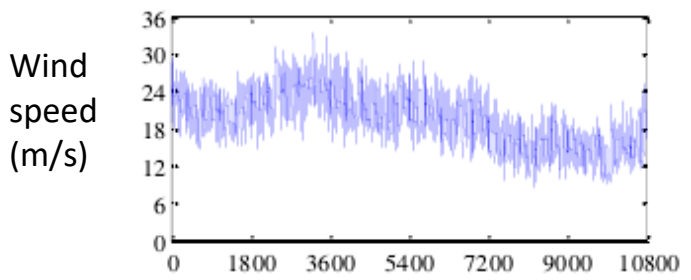

Time(s)

c) Sample 3

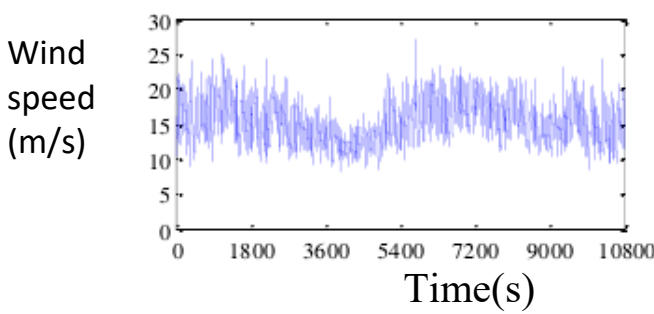

d) Sample 4

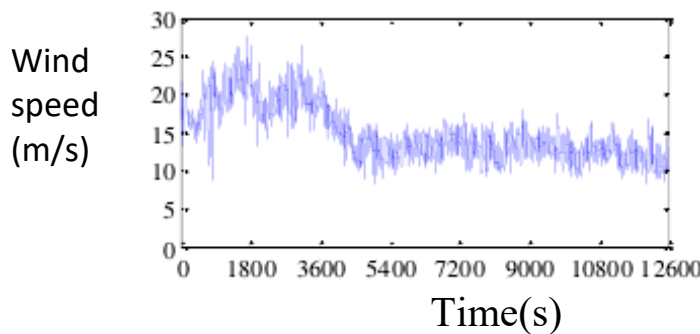

wind direction

$\left({ }^{\circ}\right)$

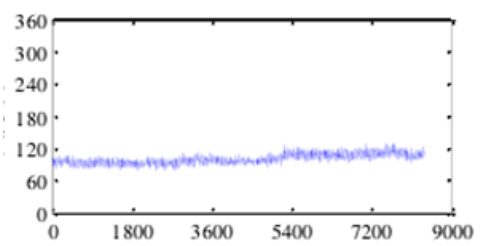

Time(s)
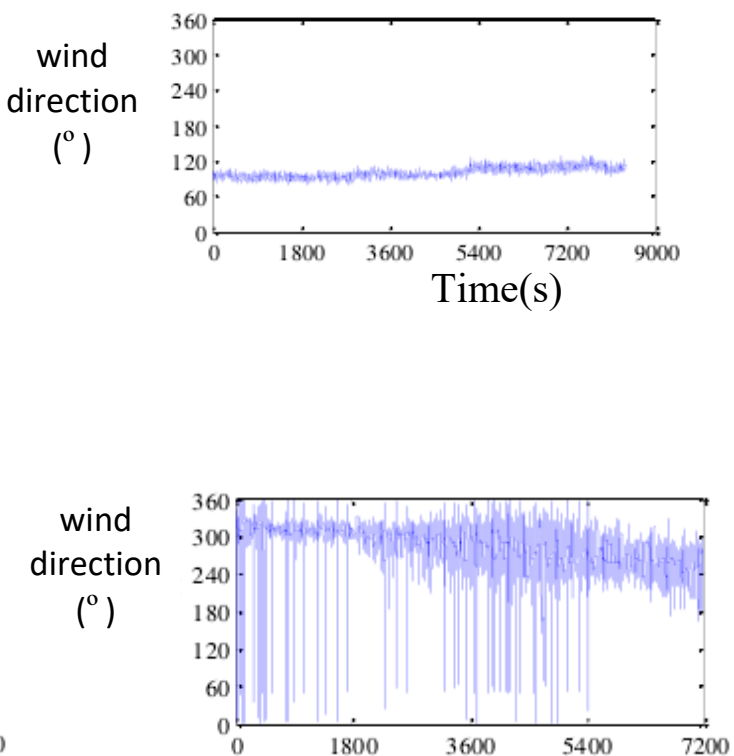

Time(s)

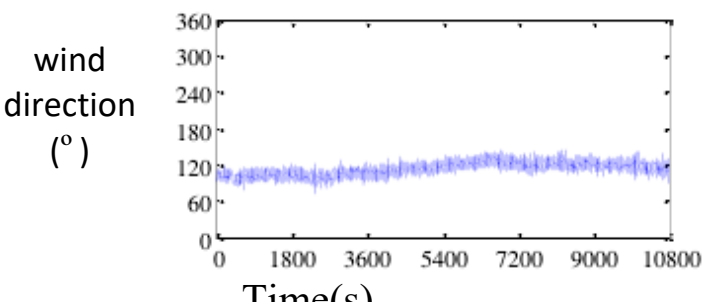

Time(s)
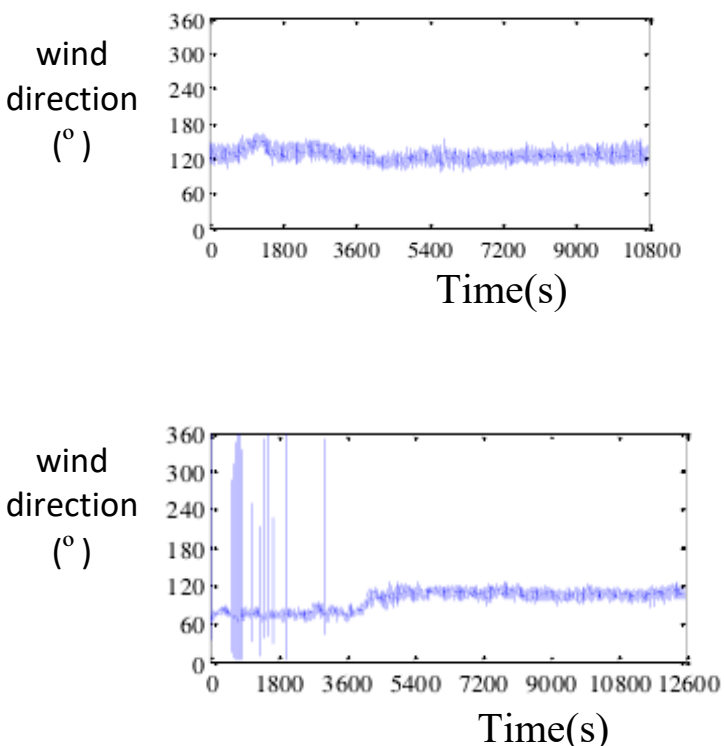

Figure 3.2 The time history of wind speed and wind direction of the 5 groups of typhoon measured samples 


\section{(2) Average wind speed and wind direction}

Figure 2-2 shows the time history of wind speed and wind direction of the 5 groups of measured samples. From the figure, it can be seen that, the average wind direction of measured sample 2 is northwest wind, and the average wind speed in about half an hour is less than $10 \mathrm{~m} / \mathrm{s}$; the average wind direction of other 4 groups of samples is mainly southeast wind and the range of variation of the total average wind direction is within $70^{\circ} \sim 140^{\circ}$, with average wind speed higher than $10 \mathrm{~m} / \mathrm{s}$.

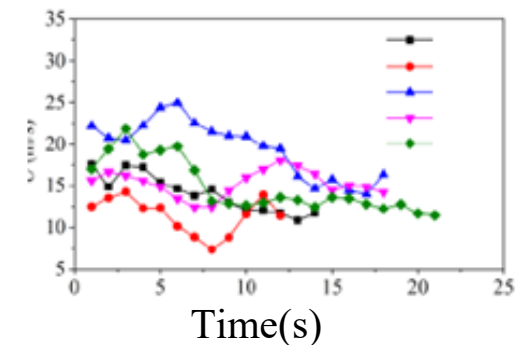

a) Average wind direction

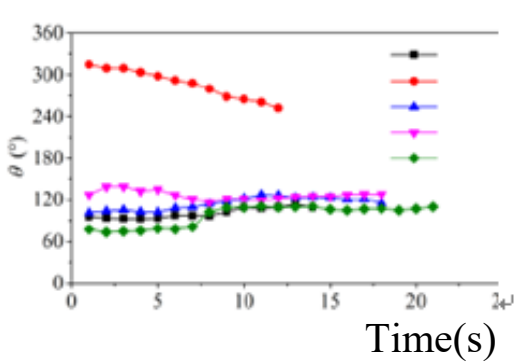

b) Average wind direction

Figure 2-2 Average wind speed and wind direction of 10min

\section{(3) Scale of turbulence}

Figure 2-3 shows the time-history of turbulent flow of 5 groups of measured samples. It can be seen from the figure that the turbulence of sample 2 is significantly larger, and the average wind speed of the large turbulence is less than $10 \mathrm{~m} / \mathrm{s}$ when the turbulence is very big. The turbulence of the other 4 samples was basically within $5 \% \sim 15 \%$, and the turbulence value of the downwind was greater than that of the across-wind direction. The reasons for the large turbulence of sample 2 are: (1) the flow wind of sample 2 passes through the mountains and urban center successively, and the surface roughness of the terrain is large; (2) there are adjacent high-rise buildings on the west side of building $\mathrm{C}$, and there are high-rise and multi-storey houses in the northwest direction. The surrounding buildings have interferences on the wind fields. (3) In the wind field of sample 2, the installation position of the anemometer is in the downstream, and the building $\mathrm{C}$ itself exerts a great disturbance to the measured data.

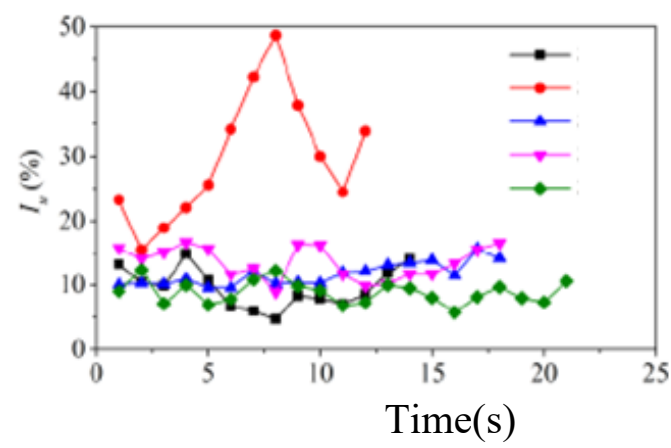

a) Average wind direction

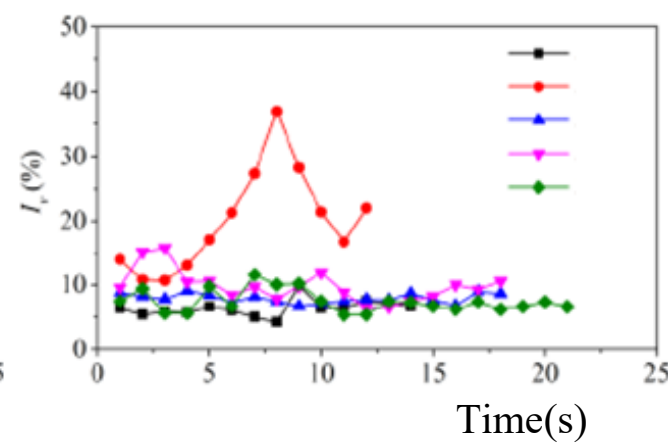

b) Average wind direction

Figure 2-3 Scale of turbulence of different measured samples

The relationship between the average scale of turbulence, and the average wind speed and average wind direction of 5 samples iss shown in Figure 3-4. As can be seen from figure 3-4 a, in addition to the large data points of the turbulence scale in sample 2 (especially the turbulence scale when the wind speed is less than $10 \mathrm{~m} / \mathrm{s}$ ), the turbulence scale varies slightly with the average wind speed. It shows that to make analysis on the measured wind speed samples with high average wind speed is one of the necessary conditions to gain steady and reliable turbulence parameters. It can be seen from Figure 3-4 $\mathrm{b}$ that the average wind direction has a great influence on the scale of turbulence. The value of the scale of turbulence with the wind direction within the scope of $60^{\circ} \sim$ $150^{\circ}$ is obviously lower than the value with the wind direction within the scope of $240^{\circ} \sim 330$; moreover, the scale of turbulence within the former scope is not sensitive to the wind direction; within the latter scope the change of wind direction has great influence on the scale of turbulence. 
As the measured data is limited, it needs further research on the influence of wind direction (corresponding to different flow topography) on the scale of turbulence.

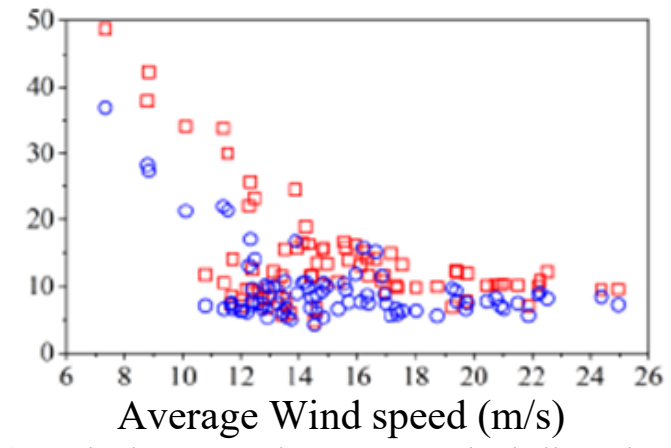

a)Turbulence and average wind direction

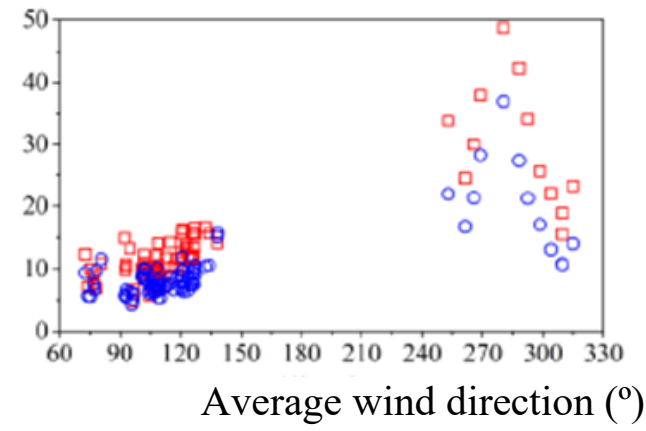

b)Turbulence and average wind direction

Figure 3-4 The relationship between the average scale of turbulence, and the average wind speed and average wind direction

After removing the turbulence value when the wind speed less than $10 \mathrm{~m} / \mathrm{s}$ in sample 2, the statistical results of the turbulence of the 5 groups are shown in table 2-2. The mean of turbulence value of sample 2 is about twice as much as the other samples, and its standard deviation is also larger. It is proved that when the wind is the northwest wind, under the influence of the flow topography and the interference of the front buildings, the turbulent degree of the wind field in the measured building significantly increases, and the data points are more discrete. The mean value of the wind direction is $8.82 \% \sim 24.17 \%$, and the mean value of the across-wind is $6.35 \% \sim 15.68 \%$; the ratio of the scales of turbulence between the along wind and the across-wind (ie: Iu: Iv) is within the range of 1:0.67 1:0.84.

Table 2-2 Statistics of scale of turbulence of different measured samples

\begin{tabular}{|c|c|c|c|c|c|c|}
\hline & & $\begin{array}{l}\text { Average } \\
(\%)\end{array}$ & $\begin{array}{l}\text { Minimum } \\
\text { Value (\%) }\end{array}$ & $\begin{array}{l}\text { Maximum } \\
\text { Value (\%) }\end{array}$ & $\begin{array}{l}\text { Standard } \\
\text { Deviation }\end{array}$ & I:I \\
\hline \multirow{2}{*}{ Sample 1} & $\begin{array}{l}\text { Along-wind } \\
\text { direction }\end{array}$ & & 4.68 & 14.84 & 3.11 & \multirow{2}{*}{$1: 0.67$} \\
\hline & $\begin{array}{l}\text { Across-wind } \\
\text { direction }\end{array}$ & & 4.22 & 9.78 & 1.29 & \\
\hline \multirow{2}{*}{ Sample 2} & $\begin{array}{l}\text { Along-wind } \\
\text { direction }\end{array}$ & & 15.44 & 33.81 & 5.84 & \multirow{2}{*}{$1: 0.65$} \\
\hline & $\begin{array}{l}\text { Across-wind } \\
\text { direction }\end{array}$ & & 10.6 & 21.97 & 4.38 & \\
\hline \multirow{2}{*}{ Sample 3} & $\begin{array}{l}\text { Along-wind } \\
\text { direction }\end{array}$ & & 9.49 & 15.59 & 1.81 & \multirow{2}{*}{$1: 0.68$} \\
\hline & $\begin{array}{l}\text { Across-wind } \\
\text { direction }\end{array}$ & & 6.67 & 9.03 & 0.73 & \\
\hline \multirow{2}{*}{ Sample 4} & $\begin{array}{l}\text { Along-wind } \\
\text { direction }\end{array}$ & & 8.85 & 16.61 & 2.56 & \multirow{2}{*}{$1: 0.72$} \\
\hline & $\begin{array}{l}\text { Across-wind } \\
\text { direction }\end{array}$ & & 6.35 & 15.74 & 2.51 & \\
\hline \multirow{2}{*}{ Sample 5} & $\begin{array}{l}\text { Along-wind } \\
\text { direction }\end{array}$ & & 5.72 & 12.30 & 1.78 & \multirow{2}{*}{$1: 0.84$} \\
\hline & $\begin{array}{l}\text { Across-wind } \\
\text { direction }\end{array}$ & & 5.31 & 11.54 & 1.74 & \\
\hline
\end{tabular}




\section{Conclusions}

Through the analysis of the influence of average wind speed and wind direction on the wind characteristics, this paper shows that selecting the data of strong wind is the basis of the characteristic parameters of the wind, and the average wind direction corresponds to the surface roughness; the correlation analysis of the wind speed on the top of three buildings show that the spatial distance between the measuring points of wind speed is the important factor to determine spatial correlation coefficient and coherence function; moreover, the general spatial correlation coefficient and coherence function value of alongwind are greater than the across-wind direction. This paper adopts wind characteristic model analysis method based on non-steady wind to make re-analysis on all the measured data of wind field, after the comparing analysis based on steady wind model analysis results, it shows that there is no big differences between the wind characterisct parameters calculated by non-steady wind model and the results based on steady wind model, but the estimation of the non-steady wind turbulence degree is more reasonable.

\section{References}

[1] Luo Yaozhi, Cai Pengcheng, Sun Bin, Tong Ruofei, Shen Yanbin, Wang Qiaqin. Wind-field Full-scale Measurement of Large-Longspan Roof of National Stadium, [J]. Vibration and Shock, 2012,03:64-68+78.

[2] Shi Wenhai, Li Zhengnong, Luo Diefeng, Zhang Chuanxiong, Liang Xiaohan, Field Research of Wind-field and Wind-pressure Characteristics of Super High-rise building in Coastal Xiamen Under the Influence of Typhoon "Catfish" [J]. Architectural Structure Journal,2012,01:1-9.

[3] Shi Wenhai, Li Zhengnong, Qin Liangzhong, Chen Lianmeng, Luo Diefeng. Contrastive Analysis of Tubulence Characteristic in Different Time Span of Surface over Land and Superaltitude [J]. Architectural Structure Journal,2012,11:18-26.

[4]. Pan Jihong. Development of Study on Wind Speed and Pressure of Field Measurement [J]. East China Jiaotong University Journal, 2015,05:73-86.

[5] Zhou Fulin, Cui Jie. Brief Discussion on Development and Trend of Anti-disaster in Civil Engineering, 2010,04:3-10 